\title{
The British 'U-turn' - yetis Herd Immunity still the solution to COVID 19?
}

Received: 22 April, 2020

Accepted: 09 June, 2020

Published: 10 June, 2020

*Corresponding author: Peter Bradshaw, School of Human and Health Sciences, University of Huddersfield, Huddersfield, UK, E-mail: p.I.bradshaw@hud.ac.uk

https://www.peertechz.com

Check for updates

\section{Peter Bradshaw*}

${ }^{1}$ School of Human and Health Sciences, University of Huddersfield, Huddersfield, UK
Herd immunity defines the level of protection from infectious diseases within a given population. It occurs naturally from exposure to a particular pathogen or, from vaccination against it. Against our understandings of this fundamental concept, the British Medical Journal reports on work published last month suggesting over half the UK population might already have been infected by coronavirus? [1]. If so, that 'immune' proportion may so well as to be entirely free from danger.

All very speculative you may think? But this incomplete work, currently conducted at the University of Oxford comes with the necessary caveats of a preliminary paper that is still to be peer-reviewed [2]. Yet its significance lies in the important questions it asks about our understandings of immunity within this present vindictive pandemic, how we best anticipate and manage disease sufferers - and authoritatively when lockdown can be safely lifted?

\section{Do coronavirus sufferers become immune?}

As the number of infected people surpasses 2.5 million worldwide, scientists internationally grapple with the most fundamental question of the pandemic namely, do people who survive the infection become immune to the coronavirus?

Although the evidence generally is totally equivocal the answer from this study is certainly a qualified yes, with some significant unknowns. Hence its hypothetical importance - that appropriate people confirmed immune could leave their homes safely to strengthen the workforce before a vaccine becomes available and in particular, health care workers who are known to be immune could continue risk-free to care for the severely ill. Ultimately, it is only through growing communal - herd immunity that any epidemic ever ends simply because there becomes a diminishing unprotected population to infect.

\section{How convincing is the evidence?}

The investigators used data on the number of fatalities and reported cases in Italy and the UK during the early phases of the current epidemic. They accept these reports mostlyon the frail elderly, the seriously sick and in effect - the most defenceless fraction of the population. Using these data from the vulnerable population, they then used conventional mathematical models to explore that fraction of the greater population susceptible to severe disease and death [2].

Their simulations concur with prior studies elsewhere that the current epidemic in Italy and the UK in the absence of interventions, will last around 2-3 months with death rates lagging behind the overall rate of infection.

Crucially however, the investigators' findings from both Italy and the UK estimate that viral transmission began 38 days before the first recorded death in Britain, which occurred on 5 March 2020 - over a month earlier than commonly believed. They the work found that, given this start date, $68 \%$ of the population would have been infected by 19 March that has,

'already led to the accumulation of significant levels of herd immunity in both countries' [2].

The political and scientific significance of Herd Immunity?

Allowing unrestrained spread of coronavirus was pursued by the current Government untilmid-March. Boththe British Health Secretary and its Chief Scientific Officer said repeatedly the aim was to achieve 'Herd Immunity' to manage the outbreak and preventa 'second wave' next winter.

Strangely during epidemic times, Secretary Hancock did not pursue conventional public health measures comprising 
rigorous testing, contact tracing and isolation. But ominous evidence began to gather that unrestrained Herd Immunity might become an unmanageable liability leading to over $60 \%$ population exposure with an estimated 250,000 deaths,

Hence on 16 March,a U-turn happened and the Government warmly embraced and launched the 'adaptive policy' advocated by Imperial College, Londonwith its lower expected death rate of 20,000 deaths - and the measures we all understand - to delay contagion through home isolation of the infected, home quarantining in symptomatic households, social distancing and curtailment of unnecessary human contact and cocooning of the over 70 s and the predisposed

Yes - work of this sort from the Oxford team sets itself up to the critique it received from purists and ideologues (Sayburn, 20200). Yet the authors' claims are reasonable-saying even if their modeling turned out to be accurate, these would not change the current strategic public health advice to reduce the spread of the virus-nor do the researchers fail to acknowledge that despite a higher level of Herd Immunity, this does not necessarily convey protection to the most defenselessamong us.

\section{The implications}

The accurate determination of current levels of Herd Immunity has such practical relevance that it just cannot be ignored. It enables the determination of how many people will require hospitalization and might conceivably die but is also the solution to the effectiveness of lockdown and the determination of its end?

Governments internationally are keen to check out of lockdown as soon as possible. Yet we in Britain are currently cluelesswhen it will be safe for us to be 'let out' - knowing full well a subsequent 'second wave' might exceed the lethality of the current epidemic? So if we are not proceeding to a catastrophic exit, how will normal life be restored?

Government spends each afternoon trying to explain in press briefings where we are going - but how much of this is just virtual is hard to tell? So are we getting the full picture or has thinking progressed at all beyond 'flattening the curve?

Lockdown has pushed us into a corner and is giving the National Health Service room 'of sorts' to cope with the immediate volume of cases and giving Government the time to think.We are thus working laudably hard to the highest moral standardsto protect our overall community from what is in reality, though not exclusively, is mainly a threat to older people.

The economy may be able to sustain the current lockdown for the next three to six months. But ultimately the concerns of the relatively less predisposed younger population whose entire economic futures are in jeopardy will surely prevail in The Government'simagination? Hence without a vaccine to confer individual immunity, the UK might still have to concede simply to a calculated lifting of the confinement restrictions, to grow naturally acquired Herd Immunity - and to end this pandemic for now - unwanted shrouds and all?

\section{References}

1. Sayburn A (2020) Covid-19: experts question analysis suggesting half UK population has been infected. BMJ 368. Link: https://bit.ly/2Yatz6g

2. Lourenco J, Paton R, Ghafari M, Kraemer M, Thompson P, et al. (2020) Fundamental principles of epidemic spread highlight the immediate need for large-scale serological surveys to assess the stage of the SARS-COV-2 epidemic. Link: https://bit.ly/30ma8ds
Discover a bigger Impact and Visibility of your article publication with

\section{Peertechz Publications}

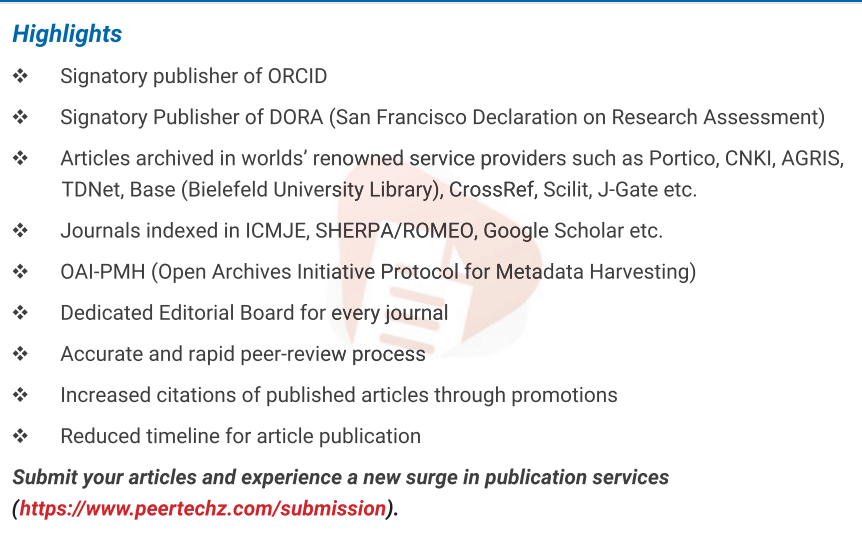

Copyright: @ 2020 Bradshaw P, et al. This is an open-access article distributed under the terms of the Creative Commons Attribution License, which permits unrestricted use, distribution, and reproduction in any medium, provided the original author and source are credited. 